\title{
Androgen Receptors Influence the Production of Pulmonary Surfactant in the Testicular Feminization Mouse Fetus
}

\author{
Heber C. Nielsen \\ Department of Pediatrics, University of Texas Health Science Center at Dallas, Texas 75235
}

\begin{abstract}
A sexual dimorphism in fetal pulmonary maturation has been described in which the female fetal lung produces surfactant earlier in gestation than the male fetal lung. This is felt to be related to the increased incidence in male newborns of the Respiratory Distress Syndrome. Dihydrotestosterone will delay surfactant production in the female fetus, and a relationship between fetal sexual differentiation and fetal lung maturation has been proposed. We hypothesized that the dimorphism in fetal surfactant production is dependent on androgen receptor function. We measured phosphatidylcholine (PC), saturated phosphatidylcholine (SPC), and sphingomyelin (S) in the amniotic fluid of fetal mice of the mouse model of testicular feminization (Tfm mouse). In this model, male carriers of the $\mathrm{X}$-linked Tfm gene have no functional androgen receptors. The mean amniotic fluid phosphatidylcholine to sphingomyelin ratio (PC/S ratio) was $28 \%$ higher in females than in normal males, and the amniotic fluid PC/S ratio of the Tfm male fetuses was the same as the females. The ratio of amniotic fluid saturated phosphatidylcholine to sphingomyelin (SPC/S ratio) was lowest in males, intermediate in females, and highest in Tfm males. A significant relationship between the fetal groups and the amniotic fluid SPC/S ratio was identified by analysis of variance. There were no differences in the whole lung phospholipid content between the three groups.

To substantiate the effect of androgen receptors, dihydrotestosterone was injected into pregnant carriers of the Tfm mutation, $2.5 \mathrm{mg} / \mathrm{d}$ from day 10 of gestation through the day of sacrifice. The amniotic fluid PC/S ratio was decreased in the female fetuses (consisting of both homozygous normal and heterozygous carriers of the $\mathrm{Tfm}$ gene), but not in the $\mathrm{Tfm}$ male fetuses. The overall result was no significant difference between the male and female amniotic fluid $\mathrm{PC} / \mathrm{S}$ ratio while the Tfm amniotic fluid PC/S ratio remained at the level of the untreated females.

We conclude that androgens affect fetal lung development via a mechanism dependent on the presence of androgen receptors.
\end{abstract}

\section{Introduction}

A sexual dimorphism in fetal pulmonary surfactant production has been described (1-3); it is characterized in many mammalian species by an increase in female fetal surfactant phos-

This work was presented in part as an abstract at the annual meeting of the Society for Pediatric Research, May 1983.

Received for publication 21 September 1984 and in revised form 5 March 1985.

J. Clin. Invest.

(c) The American Society for Clinical Investigation, Inc.

0021-9738/85/07/0177/05 \$1.00

Volume 76 , July $1985,177-181$ pholipid production. This has been implicated in the clinical observations of greater incidence of the respiratory distress syndrome $(R D S)^{1}$ in male newborns and the failure of male fetuses to respond to prenatal glucocorticoid therapy to protect against RDS $(1,4)$. Investigations of the mechanism of this sex difference have shown a relationship between sexual differentiation and fetal lung maturation (4). For example, administration of dihydrotestosterone (DHT) to pregnant rabbits during the time course of fetal sexual differentiation eliminated the sex difference by inhibiting surfactant production in the female fetus. Alternatively, the antiandrogen flutamide, when given over the same time course, eliminated the sex difference by producing an increase in fetal male surfactant production. Other evidence also indicates that a link exists between the dimorphism of fetal sexual differentiation and the observed dimorphism in fetal surfactant production (4).

Androgen could potentially influence lung development through any of several mechanisms, such as through direct activation of specific androgen receptors, indirectly by competitive inhibition of other hormone receptors, or by interference with enzyme processes. Studies to date suggest that androgen receptors may be involved in the process. Androgen receptors are present in fetal rabbit lung and human fetal lung fibroblasts $(5,6)$. Giannopoulos and Sommers Smith (5) demonstrated that androgen does not compete for glucocorticoid receptors in the fetal rabbit lung at the time when glucocorticoid receptor activation leads to stimulated surfactant synthesis. Flutamide generally exerts its antiandrogen effects by competing with androgen for its receptor; therefore, the above-mentioned effect of flutamide on male surfactant production is likely to involve androgen receptors.

To determine whether the dimorphism in fetal surfactant production is dependent on the activation of androgen receptors, we utilized the mouse model of testicular feminization ( $\mathrm{Tfm}$ mouse) in which androgen receptors are defective as the consequence of an $\mathrm{X}$-linked mutation. Male mice with the Tfm gene on the $X$ chromosome $(\mathrm{Tfm} / \mathrm{Y})$ do not have functional androgen receptors (7). We studied fetal surfactant production in the $\mathrm{Tfm}$ mouse to test whether androgen receptor function is part of the mechanism by which a sex difference in fetal lung development occurs. We postulated that the Tfm male $(\mathrm{Tfm} / \mathrm{Y})$ fetus would not show decreased surfactant production in comparison to the female fetus and that it would exhibit greater surfactant production than unaffected males.

\section{Methods}

Genetic model. The production of androgen receptors in this mouse model is controlled by the testicular feminization gene $(\mathrm{Tfm})$ which is

1. Abbreviations used in this paper: DHT, dihydrotestosterone; PC, phosphatidylcholine; RDS, respiratory distress syndrome; S, sphingomyelin; SPC, saturated phosphatidylcholine; Ta, tabby gene; Tfm, testicular feminization gene; Tfm mouse, mouse model of testicular feminization. 
located on the X-chromosome and is closely linked to a coat color gene tabby (Ta) (8). In the inbred colony of Dr. Jean D. Wilson at this institution, these two genes are cobred to produce heterozygous female carriers of one $\mathrm{Tfm}$ gene on one $\mathrm{X}$ chromosome and one tabby gene on the other $X$ chromosome $(\mathrm{Tfm} / \mathrm{Ta})$. Such heterozygous females are easily recognized as $\mathrm{Tfm}$ carriers by their coat markings. We mated $\mathrm{Tfm} / \mathrm{Ta}$ females with $\mathrm{Ta} / \mathrm{Y}$ males. The possible offspring of this mating are (Fig. 1): (a) Females with genotypes $\mathrm{Ta} / \mathrm{Ta}$ and $\mathrm{Tfm} / \mathrm{Ta}$. In terms of sexual development and growth, these are considered normal females. (b) Males which are genotype Ta/Y. These also have normal sexual development, and we expected them to also exhibit a delay in fetal pulmonary surfactant production. (c) Males which are genotype $\mathrm{Tfm} / \mathrm{Y}$ or $\mathrm{Tfm}$ males. These have a complete absence of androgen receptors in all tissues; yet, during fetal life, they produce normal amounts of testosterone and DHT. Because of the absence of androgen receptors, however, these fetuses do not masculinize, and thus, differentiate as phenotypic females.

Study design. We mated $\mathrm{Tfm} / \mathrm{Ta}$ females with $\mathrm{Ta} / \mathrm{Y}$ males as depicted in Fig. 1 and considered the day of the copulatory plug as day $\mathbf{0}$ of gestation. Studies on fetal surfactant production were carried out on the afternoon of day 17, which we called $17.5 \mathrm{~d}$. At this time, the pregnant female was killed by decapitation, and the uterus was removed intact. Each amniotic sac was carefully isolated with membranes intact, and the amniotic fluid was collected separately for each fetus. Care was taken to avoid contamination of the amniotic fluids with blood. Amniotic fluid samples with obvious blood contamination were not included in subsequent assays. After amniotic fluid collection, the fetuses were weighed, and their lungs were dissected and weighed. The fetal sex, i.e., female, male, or Tfm male, was identified by examination of the genital tract using a dissecting microscope at a magnification of $\times 15$. Tfm males can be readily distinguished from normal males by the absence of seminal vesicles, vas deferens, and epididymis.

Measurement of phospholipids. Amniotic fluids and lungs were kept on ice and stored at $-40^{\circ} \mathrm{C}$ until the time of processing. At that time, amniotic fluids from two fetuses of the same sex were combined for assay. Lungs were homogenized separately in 40 -fold wet weight of normal saline. Aliquots of the lung homogenate were utilized for assay of protein and DNA $(9,10)$. Lipids were extracted from amniotic fluids and lung homogenates by the method of Folch et al. (11). The resulting extracts were split into two aliquots. In one aliquot, phosphatidylcholine (PC) and sphingomyelin (S) were separated by thin layer chromatography on silica gel $\mathrm{H}$ thin layer chromatograms (Eastman Kodak, Rochester, NY) in chloroform:methanol:water (65:25:4). Osmium tetroxide was added to the second aliquot to isolate saturated

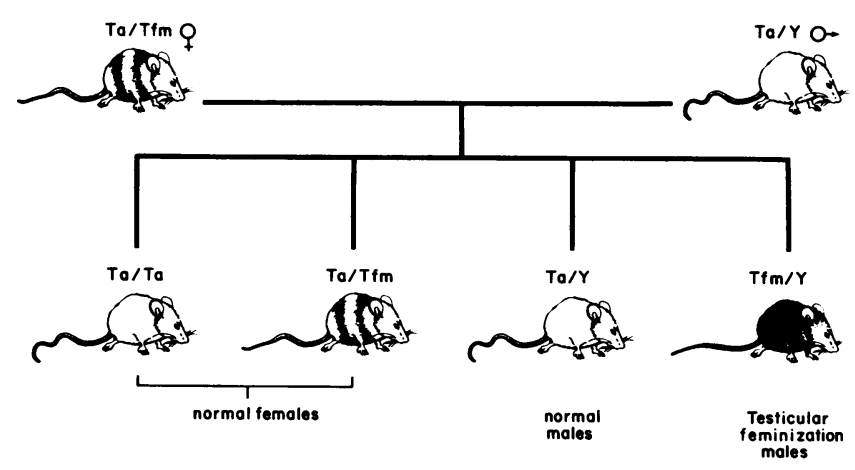

Figure 1. Pedigree of offspring of a $\mathrm{Tfm} / \mathrm{Ta}$ female mated to a $\mathrm{Ta} / \mathrm{Y}$ male. Tabby characteristics are denoted by hair coloring and kinked tail in this figure. Homozygous $\mathrm{Ta} / \mathrm{Ta}$ or $\mathrm{Ta} / \mathrm{Y}$ animals are depicted with completely unshaded coat and kinked tail; heterozygous $\mathrm{Ta} / \mathrm{Tfm}$ are depicted with striped coat and less tail kinking; and homozygous $\mathrm{Tfm} / \mathrm{Y}$ have a completely shaded coat but no kinked tail. phosphatidylcholine (SPC), as described by Mason et al. (12). The SPC was then separated by thin layer chromatography as described above. The resulting phospholipid spots were scraped and phospholipids quantitated by phosphorus assay (13). These results were expressed as the ratios of phosphatidylcholine or saturated phosphatidylcholine to sphingomyelin (PC/S and SPC/S) for the amniotic fluids, and as the ratios of PC or SPC to protein for the lungs.

DHT treatment. To substantiate a role of androgen receptors in fetal surfactant production, we injected a group of pregnant $\mathrm{Tfm} / \mathrm{Ta}$ mice with DHT, $2.5 \mathrm{mg} / \mathrm{d}$, diluted in dimethylsulfoxide, $83 \mathrm{mg} / \mathrm{ml}$ (14). Both chemicals were obtained from Sigma Chemical Co., St. Louis, MO. Injections were begun on day 10 of gestation to coincide with the period of sexual differentiation and continued daily until sacrifice on day 17.5 of gestation. This is the same protocol previously used to document androgen effects on the fetal lung (4). Amniotic fluids and fetal lungs were collected and processed as described above, except that only PC and S were measured in these amniotic fluids. Fetal sex was also identified as described above.

Statistical methods. Comparisons of values of $\mathrm{Tfm}$ and females to those of males in the untreated group and comparison of $\mathrm{Tfm}$ to female values in the DHT-treated group were made by using the onesided Student's $t$ test. A one-sided test was utilized because the original hypothesis was constructed to indicate only whether the female and the $\mathrm{Tfm}$ results were greater than the males (15). As a further check, analysis of variance using linear regression with dummy variables was employed to detect differences across the three sex groups (15). When the variances between groups were markedly different, Welch's correction to one-way analysis of variance was used (16). All other comparisons of means used a two-sided $t$ test.

\section{Results}

No differences between the three types of fetuses (female, male, and $\mathrm{Tfm}$ male) were detected in fetal body weights or in lung weights (Table I). Injection of DHT into the pregnant mother resulted in increased fetal wastage, based on smaller litter size and greater number of resorption sites in the uterus

Table I. Body Weight, Lung Weight, and Lung Phospholipid Content of Untreated and DHT-treated Fetal Mice

\begin{tabular}{|c|c|c|c|c|}
\hline & $\begin{array}{l}\text { Body } \\
\text { weight }\end{array}$ & $\begin{array}{l}\text { Lung } \\
\text { weight }\end{array}$ & $\begin{array}{l}\mu \mathrm{g} P C / \mathrm{mg} \\
\text { protein }\end{array}$ & $\begin{array}{l}\mu \mathrm{g} \mathrm{SPC} / \mathrm{mg} \\
\text { protein }\end{array}$ \\
\hline & $m g$ & $m g$ & & \\
\hline \multicolumn{5}{|l|}{ Untreated } \\
\hline Male & $\begin{array}{l}847 \pm 113 \\
n=30\end{array}$ & $\begin{array}{l}28.8 \pm 7.4 \\
n=30\end{array}$ & $\begin{array}{l}36.2 \pm 6.8 \\
n=23\end{array}$ & $\begin{array}{l}10.8 \pm 3.1 \\
n=21\end{array}$ \\
\hline Female & $\begin{array}{l}824 \pm 110 \\
n=59\end{array}$ & $\begin{array}{l}27.0 \pm 6.9 \\
n=59\end{array}$ & $\begin{array}{l}37.1 \pm 8.4 \\
n=33\end{array}$ & $\begin{array}{c}9.3 \pm 2.4 \\
n=21\end{array}$ \\
\hline $\mathrm{Tfm}$ & $\begin{array}{l}839 \pm 102 \\
n=26\end{array}$ & $\begin{array}{l}27.5 \pm 5.7 \\
n=26\end{array}$ & $\begin{array}{l}33.0 \pm 7.6 \\
n=23\end{array}$ & $\begin{array}{c}9.0 \pm 2.4 \\
n=28\end{array}$ \\
\hline DHT-treat & & & & \\
\hline Male & $\begin{array}{l}815 \pm 213 \\
n=24\end{array}$ & $\begin{array}{l}24.6 \pm 8.8 \\
n=19\end{array}$ & $\begin{array}{l}25.9 \pm 5.8^{*} \\
n=10\end{array}$ & $\begin{array}{c}7.7 \pm 0.9 \\
n=10\end{array}$ \\
\hline Female & $\begin{array}{l}817 \pm 171 \\
n=43\end{array}$ & $\begin{array}{l}24.1 \pm 7.2 \\
n=35\end{array}$ & $\begin{array}{l}28.8 \pm 5.6^{*} \\
n=26\end{array}$ & $\begin{array}{l}8.8 \pm 2.0 \\
n=28\end{array}$ \\
\hline $\mathrm{Tfm}$ & $\begin{array}{l}946 \pm 224 \\
n=18\end{array}$ & $\begin{array}{l}29.3 \pm 8.9 \\
n=16\end{array}$ & $\begin{array}{l}27.7 \pm 6.3 \\
n=10\end{array}$ & $\begin{array}{c}9.6 \pm 1.8 \\
n=10\end{array}$ \\
\hline
\end{tabular}

All numbers represent the mean $\pm \mathrm{SD}$ of the indicated number of fetuses. * Value significantly less than untreated value of same sex, $P<0.001$, twotailed test. 
(data not shown). DHT treatment also caused an increase in the frequency of growth-retarded fetuses (defined as fetal weight $<75 \%$ of the average weight of untreated fetuses), distributed equally among the three types of fetuses. No studies of amniotic fluid or lung phospolipid were done on growthretarded fetuses. Mean fetal weights and lung weights, however, were calculated by including all fetuses in any litter from which at least one amniotic fluid was studied, and therefore, do include some growth-retarded fetuses. The inclusion of these growth-retarded fetuses did not significantly alter the mean body and lung weights. These mean body and lung weights were not significantly different from controls (Table I).

\section{Control group}

Lung phospholipids. No significant differences occurred in the total PC and SPC content of the lung when the three groups were compared. When expressed as a ratio of lung phospholipid to lung protein, no significant differences were present (Table I). PC and SPC were also measured in the lungs of fetuses from DHT-treated mothers. The mean PC per milligram of protein ratios of treated females and treated males were lower than the mean PC per milligram of protein ratios of control females and males, respectively, while the ratios in the $\mathrm{Tfm}$ animals were not significantly affected (Table I). The mean SPC per milligram protein ratios of the treated fetuses were not significantly different from controls (Table I). No differences were found in the mean lung protein per lung DNA ratios (data not shown) either in control or DHT-treated fetuses. We interpreted these data as evidence that female-male differences in amniotic fluid phospholipids, if any, represent differences which are specific to surfactant production as opposed to total cellular phospholipid production.

Control $S P C / S$ ratio. The mean amniotic fluid SPC/S ratio for the three groups of control fetuses is shown in Fig. 2. A direct comparison of the mean $\mathrm{Tfm} \mathrm{SPC} / \mathrm{S}$ ratio to the mean male SPC/S ratio indicated only a trend towards a difference $(P=0.10)$. Use of analysis of variance comparing the three groups, however, indicated a significant relationship between fetal group and the SPC/S ratio $(P$ $=0.05$ ).

Control PC/S ratio. The mean amniotic fluid PC/S ratio for the three groups of control fetuses is shown in Fig. $3 A$. The mean $\mathrm{PC} / \mathrm{S}$ ratio of the male fetuses was significantly less than that of the Tfm fetuses $(P=0.04)$ and of the female fetuses $(P=0.04)$ when compared separately by Student $t$ test. One-way analysis of variance with Welch's correction for unequal variance also indicated a significant relationship between the fetal group and the $\mathrm{PC} / \mathrm{S}$ ratio $(P=0.04)$.

DHT treatment group. Only the $\mathrm{PC} / \mathrm{S}$ ratio was measured in the DHT-treated group because this measurement

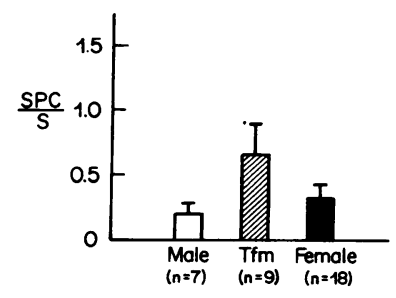

Figure 2. Amniotic fluid SPC/S ratio of nontreated fetuses. Each bar represents the mean $\pm \mathrm{SE}$ of the indicated number of pooled amniotic fluid samples. A relationship between fetal group and the SPC/ $S$ ratio was identified at $P=0.05$ by analysis of variance.
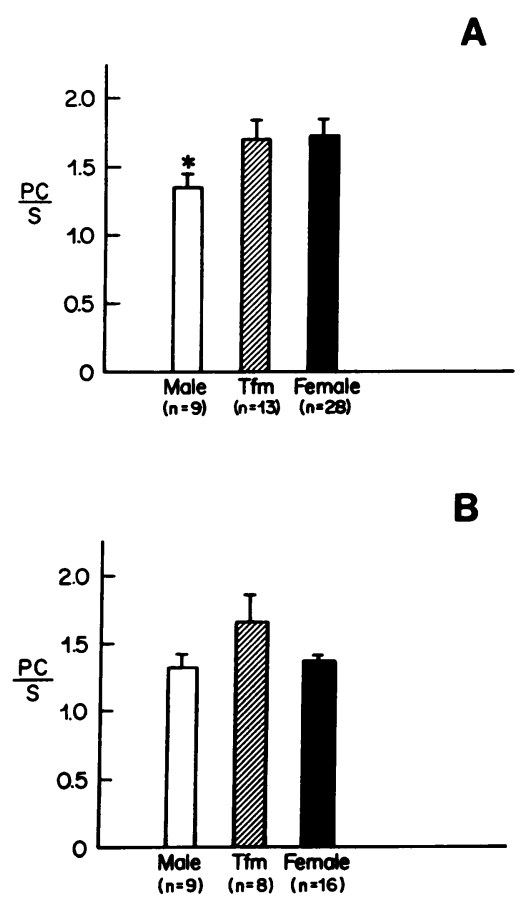

Figure 3. (A) Amniotic fluid $\mathrm{PC} / \mathrm{S}$ ratio of nontreated fetuses. Each bar represents the mean $\pm \mathrm{SE}$ of the indicated number of pooled amniotic fluid samples. A relationship between fetal group and the $\mathrm{PC} / \mathrm{S}$ ratio was identified at $\boldsymbol{P}=\mathbf{0 . 0 4}$ by analysis of variance. *, male significantly less than either female or Tfm by $t$ test, $P=0.04$. (B) Amniotic fluid PC/S ratio of DHT-treated fetuses. Each bar represents the mean $\pm \mathrm{SE}$ of the indicated number of pooled amniotic fluid samples. The female mean of this figure was significantly less than the female mean in $(A)(P=0.03$, two-tailed $t$ test $)$. A comparison of the mean female and mean $\mathrm{Tfm}$ ratios fell short of statistical significance $(P=0.07)$.

had shown the clearest results in the control experiment. DHT had no apparent effect on the amniotic fluid PC/S ratio of the $\mathrm{Tfm}$ fetus, but lowered the female $\mathrm{PC} / \mathrm{S}$ ratio to a level comparable with that of the male fetus (Fig. 3 $B)$. The amniotic fluid PC/S ratio of DHT-treated females (Fig. $3 B$ ) was significantly lower than untreated female controls (Fig. $3 A)(P=0.03$, two-tailed $t$ test). The mean $\mathrm{PC} / \mathrm{S}$ ratio of $\mathrm{Tfm}$ and of male fetuses was not significantly altered by DHT treatment (Figs. $3 A$ and $B$ ). A comparison of the mean PC/S ratio of the DHT-treated females to the mean PC/S ratio of the DHT-treated Tfm fetuses by $t$ test suggested that the DHT-treated Tfm PC/S ratio was greater than the DHT-treated female PC/S ratio; however, this fell short of statistical significance $(P=0.07$, one-way test).

\section{Discussion}

Most of the previous work documenting a female advantage in mammalian surfactant production has been done in rabbits and rats (2-4). The development of surfactant synthesis and secretion has been less well studied in the fetal mouse. We could find no other reports of mouse amniotic fluid phospholipids. We chose to study these fetuses at $17.5 \mathrm{~d}$ of gestation because the late gestation surge in surfactant production appears to occur around this point in time in the fetal mouse, as indicated by the appearance of lamellar bodies in electron 
micrographs of the mouse lung (17), by an increase in surface activity in the mouse lung homogenate (17), and by increases in the activity of some enzymes felt to be involved in the incorporation of choline into PC and the remodeling of PC into SPC $(18,19)$. In addition, we noted that fetal mouse amniotic fluid volume is markedly reduced after $17.5 \mathrm{~d}$, a phenomenon which, in our experience with rabbits and rats, occurs after lung surfactant production is well under way.

The present study documents a $28 \%$ increase in the mean amniotic fluid $\mathrm{PC} / \mathrm{S}$ ratio of female fetuses over male fetuses in the mouse. While this appears to be a less striking femalemale difference than has been described in the fetal rabbit lung lavage (2), we feel that it has biologic importance. Since these are mean values, this indicates that more females will have "high" PC/S values, i.e., greater surfactant production, while more males will have "low" PC/S values. If RDS is caused by surfactant deficiency, then clearly more males would be at risk than females. Human amniotic fluid sex differences in the $\mathrm{PC} / \mathrm{S}$ ratio are comparatively smaller (for example, the female mean PC/S ratio is $15 \%$ higher than the male at $32 \mathrm{wk}$ of gestation); yet, these differences are large enough to contribute to a greater risk of RDS in the male newborn, as we have previously reported (1). The male-female differences documented in the $\mathrm{PC} / \mathrm{S}$ ratio of rabbit amniotic fluid are similar to those described here for the mouse (2). Furthermore, in the rabbit model, amniotic fluid phospholipids, particularly the $\mathrm{PC} / \mathrm{S}$ ratio, were less sensitive indicators of the sex difference than were lung lavage phospholipids (2). This is probably because the fetal lung liquid is "diluted" in the amniotic fluid pool. In the rabbit, physiologic and anatomic parameters of lung function and development substantiate the presence of a female advantage in fetal lung development (20). Other measurements in the mouse fetus, such as lung lavage phospholipids, pressure-volume relationships, or surface balance measurements of surfactant function, are simply not feasible because of the very small lung size. We feel that if such studies were possible they would substantiate the biologic relevence of our findings in light of the agreement of our amniotic fluid data with that of humans and rabbits.

The presence of growth retardation in some DHT-treated fetuses could potentially be attributed to an overall toxic effect of DHT or dimethylsulfoxide on the fetus. An impairment of fetal growth could also be blamed for the lower PC/S ratio observed in the treated females. However, we feel that the observed changes in the $\mathrm{PC} / \mathrm{S}$ ratio were not due to a toxicityrelated alteration in fetal development for three reasons. First, there was no apparent effect of DHT administration on the PC/S ratio of either the males or the Tfm fetuses. Second, growth retardation was equally distributed among the three sexes and accounted for a minority of the fetuses, and third, we studied only those fetuses who were not apparently growth retarded. In addition, only the concentration of whole lung PC appeared significantly affected by treatment, and this only in males and females but not in the $\mathrm{Tfm}$ fetuses.

The lack of androgen receptors in all tissues of the $\mathrm{Tfm}$ mouse is well-documented (7). Therefore, the findings that the Tfm amniotic fluid PC/S ratio was not different from females and was not lowered by exogenous androgen while the female $\mathrm{PC} / \mathrm{S}$ ratio was lowered strongly indicates that androgen acts to alter fetal lung development via androgen receptors. The lack of a sex difference in lung androgen receptor number during late gestation, as described in the rabbit, does not conflict with this (5). Nielsen and Torday (unpublished data) indicate that androgens act on the fetal lung at a point much earlier in gestation than that at which receptors have been studied. The sex difference in lung development may easily arise during the period of a maximum sex difference in circulating androgens, which occurs much earlier in relation to fetal lung development (21).

An interesting feature of this model is that one-half of the female fetuses are heterozygous for the $\mathrm{Tfm}$ gene (one half are $\mathrm{Tfm} / \mathrm{Ta}$ and one half are $\mathrm{Ta} / \mathrm{Ta}$ ), and therefore, have only half as much functional androgen receptor as their homozygous littermates (8). The female fetus does have some endogenous androgen. In addition, female fetuses of polytocous mammals receive androgen from male neighbors in the uterus which affects some aspects of sexual differentiation $(22,23)$. In the rabbit the proximity of male neighbors to the female fetus has been shown also to be associated with some decrease in surfactant production in the female fetus (4). We could not distinguish which female fetuses carried the Tfm gene, and amniotic fluids were combined without regard to the presence of in utero male neighbors. It is possible that an interaction of androgen and the female genotype may have led to variability in female lung development. Thus, we speculate that $\mathrm{Ta} / \mathrm{Ta}$ females may have had a tendency to be slightly delayed in comparison to $\mathrm{Tfm} / \mathrm{Ta}$ females and $\mathrm{Tfm}$ males. This would explain the observations that the SPC/S ratio of the females was intermediate between the male and $\mathrm{Tfm}$ values and that the variance in the female $\mathrm{PC} / \mathrm{S}$ ratios was increased. The timing of this experiment was apparently early enough in gestation to catch the very early changes in SPC production during lung maturation. Since the degree of female variability secondary to heterogeneity of the $\mathrm{Tfm}$ gene is uncertain, it is important that the administration of DHT significantly lowered the female $\mathrm{PC} / \mathrm{S}$ ratio compared with untreated females, but did not affect either the male or Tfm PC/S ratio. Androgen clearly affects lung surfactant production when some androgen receptors are present, even in decreased amounts, but does not affect surfactant production when androgen receptors are completely absent.

In conclusion, the expression of a sex difference in fetal surfactant production requires the presence of androgen receptors. It is unclear at this time if this represents a stimulation of lung receptors leading directly to a delay in the differentiation and specialization of Type II cells in the lung. An alternative possibility is that androgen receptors of some other organ, possibly within the hypothalamo-pituitary-adrenal axis, are stimulated leading to an alteration in the balance of hormones active in regulating fetal lung maturation. This chain of events has been documented for androgen effects on nongonadal tissues; for example, androgen regulates hepatic enzymes via its action on the somatostatin-growth hormone axis in the pituitary (24). While early reports from Torday (25) suggest that androgen acts directly on the developing lung, this question requires further investigation.

\section{Acknowledgments}

We thank Dr. Jean D. Wilson and Dr. Carol M. Wilson for the animals used and for valuable advice.

This work supported by grants from the American Lung Association and the National Institutes of Health (5R23-HL29722 and 5P01HD13912). 


\section{References}

1. Torday, J. S., H. C. Nielsen, M. Fencl, and M. E. Avery. 1981. Sex differences in fetal lung maturation. Am. Rev. Respir. Dis. 123: 205-208.

2. Nielsen, H. C., and J. S. Torday. 1981. Sex differences in fetal rabbit pulmonary surfactant production. Pediatr. Res. 15:1245-1247.

3. Torday, J. S., and K. E. Dow. 1984. Synergistic effect of triiodothyronine and dexamethasone on male and female fetal rat lung surfactant synthesis. Dev. Pharmacol. Ther. 7:133-139.

4. Nielsen, H. C., H. M. Zinman, and J. S. Torday. 1982. Dihydrotestosterone inhibits fetal rabbit pulmonary surfactant production. J. Clin. Invest. 69:611-616.

5. Giannopoulos, G., and S. K. Sommers Smith. 1982. Androgen receptors in fetal rabbit lung and the effect of fetal sex on levels of circulating hormones and pulmonary hormone receptors. J. Steroid Biochem. 17:461-465.

6. Sultan, C., B. R. Migeon, S. W. Rothwell, M. Maes, N. Zerhouni, and C. J. Migeon. 1980. Androgen receptors and metabolism in cultured human fetal lung fibroblasts. Pediatr. Res. 13:67-69.

7. Verhoeven, G., and J. D. Wilson. 1976. Cytosol androgen binding in submandibular gland and kidney of the normal mouse and the mouse with testicular feminization. Endocrinology. 99:79-92.

8. Lyon, M. F., and S. G. Hawkes. 1970. X-linked gene for testicular feminization in the mouse. Nature (Lond.). 227:1217-1219.

9. Lowry, O. H., N. J. Rosebrough, A. L. Farr, and R. J. Randall. 1951. Protein measurements with the Folin phenol reagent. J. Biol. Chem. 193:265-275.

10. Burton, K. 1956. A study of the conditions and mechanisms of the diphenylamine reaction for the colorimetric determinations of deoxyribonucleic acid. Biochem. J. 62:315-323.

11. Folch, J., M. Lees, and G. H. Sloane-Stanley. 1957. A simple method for the isolation and purification of total lipids from animal tissues. J. Biol. Chem. 226:497-509.

12. Mason, R. J., J. Nellenbogen, and J. A. Clements. 1976. Isolation of disaturated phosphatidylcholine with osmium tetroxide. $J$. Lipid. Res. 17: 281-284.
13. Bartlett, R. G. 1959. Phosphorus assay in column chromatography. J. Biol. Chem. 234:466-471.

14. Goldstein, J. L., and J. D. Wilson. 1972. Studies on the pathogenesis of the pseudohermaphroditism in the mouse with testicular feminization. J. Clin. Invest. 51:1647-1658.

15. Snedecor, G. W., and W. G. Cochran. 1967. Statistical Methods. Iowa State University Press, Ames, IO. 593 pp.

16. Zar, J. H. 1974. Biostatistical Analysis. Prentice Hall, Englewood, NJ. 131.

17. Buckingham, S., and M. E. Avery. 1962. Time of appearance of lung surfactant in the fetal mouse. Nature (Lond.). 193:688-689.

18. Oldenberg, V., and L. M. G. Van Golde. 1977. The enzymes of phosphatidylcholine biosynthesis in the fetal mouse lung. Biochim. Biophys. Acta. 489:454-465.

19. Brehier, A., and S. A. Rooney. 1981. Phosphatidylcholine synthesis and glycogen depletion in fetal mouse lung: developmental changes and the effects of dexamethasone. Exp. Lung Res. 2:273-287.

20. Kotas, R. V., and M. E. Avery. 1980. The influence of sex on fetal rabbit lung maturation and the response to glucocorticoid. $\mathbf{A m}$. Rev. Respir. Dis. 121:377-380.

21. Veyssiere, G., M. Berger, C. Jean-Faucher, M. de Turkheim, and C. Jean. 1980. Evolution de la testosteronemie chez le foetus de lapin au cours de l'organogese sexuelle. C. R. Acad. Sci. Paris, Ser. D. 290:583-590.

22. Meisel, R. L., and I. L. Ward. 1981. Fetal female rats are masculinized by male littermates located caudally in the uterus. Science (Wash. DC). 213:239-241.

23. McDermott, N. J., R. Gandelman, and J. M. Reinisch. 1978. Contiguity to male fetuses influences ano-genital distance and time of vaginal opening in mice. Physiol. Behav. 20:661-663.

24. Gustafsson, J.-A., S. Eden, P. Eneroth, T. Hokfelt, O. Isaakson, J.-O. Jansson, A. Mode, and G. Norstedt. 1983. Regulation of the sexual dimorphism in hepatic metabolism by the somatostatin-growth hormone axis. J. Steroid Biochemistry. 19:691-698.

25. Torday, J. S. 1984. Direct pharmacologic effects of DHT on the alveolar Type II cell in vitro. Pediatr. Res. 18:146A. (Abstr.) 